Published in final edited form as:

Pediatr Exerc Sci. 2013 May ; 25(2): 238-247.

\title{
Resting IL-6 and TNF- $\alpha$ Level in Children of Different Weight and Fitness Status
}

\author{
Peter Hosick, Robert McMurray, A. Hackney, Claudio Battaglini, Terry Combs, and Joanne \\ Harrell \\ Hosick is with the Dept. Physiology and Biophysics, University of Mississippi Medical Center, \\ Jackson, MS. McMurray, Hackney, Battaglini, and Combs are with the Dept. of Exercise and \\ Sport Science, University of North Carolina, Chapel Hill, NC. Harrell is with the School of Nursing, \\ University of North Carolina, Chapel Hill, NC
}

\section{Abstract}

Reports suggest children with high aerobic fitness $\left(\mathrm{VO}_{2 \max } ; \mathrm{mL} / \mathrm{kg} / \mathrm{min}\right)$ have healthier profiles of TNF- $\alpha$ and IL-6; however, research has not accounted for differences in adiposity between highfit and low-fit individuals. Thus, this study examined differences in inflammatory markers of obese and normal weight children of different fitness levels, using two different $\mathrm{VO}_{2 \max }$ units: per unit of fat free mass $\left(\mathrm{VO}_{2} \mathrm{FFM}\right)$ or total body mass $\left(\mathrm{VO}_{2} \mathrm{~kg}\right)$. Children $(n=124$; ages 8-12) were divided into four matched groups; normal weight high-fit (NH), normal weight low-fit (NL), obese high-fit (OH), and obese low-fit (OL). Height, weight, skinfolds, body mass index (BMI), and predicted $\mathrm{VO}_{2 \max }$ were measured and a morning, fasting blood sample taken. IL-6 was elevated in the NL and OL groups compared with the NH group, as well as the OL group compared with the $\mathrm{OH}$ group. No differences were found in TNF- $\alpha$. The relationship between IL- 6 or TNF- $\alpha$ and the two units of predicted $\mathrm{VO}_{2 \max }$ did not differ suggesting that either $\mathrm{VO}_{2} \mathrm{FFM}$ or $\mathrm{VO}_{2} \mathrm{~kg}$ can be used to describe aerobic power when studying inflammation and exercise in youth. The relationship between IL- 6 or TNF- $\mathrm{a}$ and predicted $\mathrm{VO}_{2 \max }$, whether expressed per mass or per fatfree mass was similar, suggesting that both can be used to describe aerobic power when studying inflammation and exercise in youth. Given the polar design of this study, this relationship should be confirmed including overweight subjects.

Adipose tissue is one of the main sites of production of tumor necrosis factor- $\alpha$ (TNF- $\alpha$ ) and interleukin-6 (IL-6) and circulating levels of these cytokines are directly related to the amount of adipose tissue $(3,6,7,10,11,13,14)$. From a health perspective, elevated circulating TNF- $\alpha$ and IL-6 have been proposed as markers of inflammation used to link obesity with insulin resistance and diabetes, as well as atherosclerosis $(7,13)$. Thus, obesity has been characterized as a low-grade inflammatory state (7).

In contrast to obesity, increased cardiorespiratory or aerobic fitness $\left(\mathrm{VO}_{2 \max }\right)$ has been associated with reduced levels of cytokines in adults (2) and, in some way, may positively influence the relationship between obesity and cytokines. However, very little research has explored this interrelationship in children. Although studies of children have examined the associations between fitness, fatness, obesity, and cytokines, only one study was found that examined the relationship of obesity and inflammation in high-fit and low-fit adolescents (11). Results of that study suggest that TNF-a level is primarily determined by fitness level and the elevated levels of IL-6 associated with obesity is reduced if the obesity is accompanied by an elevated level of aerobic fitness. Thus, obese children with an increased level of aerobic fitness may have reduced TNF- $a$ and IL-6 levels (11). However, the author's definition of fitness ( $>5$ MET max capacity) and obesity (BMI $>22.5 \mathrm{~kg} / \mathrm{m}^{2}$ ) does not represent the typical range of fitness or obesity for children, thus, the need for further research in this area. 
When examining the associations between obesity related inflammation and aerobic fitness one issue of concern is the unit used to express aerobic fitness. The most common metric used is oxygen uptake relative to total body mass $\left(\mathrm{VO}_{2 \mathrm{max}} ; \mathrm{ml} / \mathrm{kg} / \mathrm{min}\right)$. However, using a metric that includes total body mass may be problematic because body mass includes both lean and fat mass and, as previously mentioned, fat mass is associated with elevated cytokines. Using a metric that includes only fat free mass, such as oxygen uptake per kilogram fat free mass per minute $\left(\mathrm{VO}_{2} \mathrm{FFM}\right)$ may remove the confounding issue of fat mass and theoretically present a more accurate depiction of the relationship between inflammation and aerobic fitness. Therefore the purpose of this study is to explore a metric for fitness that removes the impact of increased levels of adipose tissue to determine which unit is most appropriate when including obese and normal weight children. In addition, we attempt to determine if differences in TNF- $\alpha$ and IL- 6 exist between adolescents who are obese or of normal weight and possess high and low aerobic fitness.

\section{Methods}

\section{Subjects}

A total of 124 children were selected from 1486 participants in Cohort five of the

Cardiovascular Health in Children III study, based on their body mass and fitness status. The CHIC III study was an investigation of youth from rural areas exploring risk factors for cardiovascular disease and the metabolic syndrome. Of the original 1486 participants, the sex and race distribution was $\sim 50 \%$ male, 50\% female, 55\% African American, $37 \%$ Caucasian, and $8 \%$ other races, with a mean age was $9.7 \pm 1.1$ years old. The subsample used for the present investigation included subjects aged $10.0 \pm 0.9$ (52 female, 72 male, 72 African American, 39 Caucasian, and 13 other races). Subjects were chosen and matched in 4 groups based upon their weight and their predicted aerobic fitness $\left(\mathrm{pVO}_{2} \mathrm{max}\right)$ status: obese high-fit $(\mathrm{OH})$, obese low-fit $(\mathrm{OL})$, normal weight high-fit $(\mathrm{NH})$, and normal weight low-fit (NL). Only youth in Tanner stages 1-3 were included in the study. All subjects gave written assent and their parents provided consent before participation, by signing the institutional IRB approved forms.

\section{Data Collection Procedures}

All anthropometric and exercise testing was completed in the subject's school during the school day. Blood was drawn early in the morning, also at the school site. Height was measured using a standard stadiometer (Perspective Enterprises, Portage, MI). Body mass was determined using a calibrated electronic scale (Model 2101L, Healthometer Medical, Bridgewater. IL). Body mass index (BMI) was calculated: [mass (kg)/height $\left.(\mathrm{m})^{2}\right]$. Pubertal status was estimated using the Pubertal Development Scale (19), a sex-specific selfadministered questionnaire with 5-item subscales. Skinfolds were measured in triplicate using calibrated Lange Skinfold calipers (Cambridge Scientific, Cambridge, MD) from the subscapula and triceps (18). These measurements were used to estimate body fat percentage using sex, race, and maturation level based formulas (21). Fat free mass (FFM) was determined by subtracting predicted body fat percent (expressed as a decimal) from one and multiplying by the subjects total body mass $(\mathrm{kg})$.

Predicted aerobic power $\left(\mathrm{pVO}_{2} \max \right)$ in absolute units of $\mathrm{mL} / \mathrm{min}$ was estimated from a submaximal cycle ergometer test using the methods of McMurray et al. (17). The test consisted of three, 3-min stages, each progressing in exertion level by $0.5 \pm 1.0 \mathrm{~W} / \mathrm{kg}$ body mass. Estimated $\mathrm{VO}_{2 \max }$ was predicted from the heart rate responses at each of the three levels (power outputs), in comparison with the known oxygen uptake at each power output, accounting for resting metabolic rate. This method has been shown to produce correlations as high as $r=.80(S E=4 \mathrm{~mL} / \mathrm{kg} / \mathrm{min} ; 17)$ with measured $\mathrm{VO}_{2 \max }$. The cycle ergometers 
used in testing were calibrated BodyGuard (model 990), Tunturi magnetic-braked Tunuri Oy Ltd., (Turku, Finland), or Monarch (model 818; Monark, Varberg, Sweden) cycle

ergometers. Predicted $\mathrm{VO}_{2 \max }(\mathrm{mL} / \mathrm{min})$ was divided by FFM giving the metric of $\mathrm{mL}$ of $\mathrm{O}_{2}$ per kilogram of fat free mass per min $\left(\mathrm{mL} / \mathrm{kg}_{\mathrm{FFM}} / \mathrm{min}\right)$ or $\mathrm{VO}_{2} \mathrm{FFM}$. Predicted $\mathrm{VO}_{2 \max }$ was also computed in terms of $\mathrm{mL}$ of oxygen per kilogram body mass $(\mathrm{mL} / \mathrm{kg} / \mathrm{min})$ or $\mathrm{VO}_{2} \mathrm{~kg}$.

\section{Group Determination}

Weight status was determined based upon the Centers for Disease Control and Prevention (CDC) growth charts from the year 2000 which define normal, over-weight and obese in children and adolescents (4). BMI was used for classification because no method for classification has been developed for skinfolds. Normal weight was defined as $<85$ th and $>$ fifth BMI percentile for age and sex. Obese was defined as $>95$ th BMI percentile for age and sex. Fitness was determined based upon predicted $\mathrm{VO}_{2} \mathrm{FFM}$. $\mathrm{VO}_{2} \mathrm{FFM}$ was chosen to reduce the influence of fatness which is confounded in the unit of $\mathrm{VO}_{2} \mathrm{~kg}$. Fitness cut-points were developed (unpublished data) based on data from CHIC cohorts I, II, and III, collected from 1992 to 2005, representing 3235 adolescents from age 8-12. Subjects that were in the 66th percentile or above for $\mathrm{VO}_{2} \mathrm{FFM}$ were included in the high fitness group; those with $\mathrm{VO}_{2} \mathrm{FFM}$ less than the 33 rd percentile were included in the low fitness group. $\mathrm{VO}_{2} \mathrm{FFM}$ cutoffs by age and sex previously published elsewhere (12); refer to Table 1 for summary.

All subjects in the original study fitting both the obesity and high fitness criteria with complete data were included in the $\mathrm{OH}$ group. This decision was made because of the small number of youth that met the criteria. Of the original 1486 subjects, 44 in Tanner Stages 1-3 met the criteria of being obese and highly fit, but only 31 of these had complete data and blood samples. Selection into the NH, NL, or OL group was done matching sex and pubertal status to the $\mathrm{OH}$ group after having met the individual group criteria for weight and fitness status.

\section{Blood Analysis}

Subjects were called the day before blood draws and reminded to not eat anything and drink only water before their blood was drawn. Upon arrival subjects confirmed their overnight fast and then a blood sample was obtained from the antecubital space. The blood samples were centrifuged, separated into individual mircocentrifuge tubes with $\sim 0.5 \mathrm{ml}$ sample per tube, then placed on dry ice to be transported to our storage facility, where they were processed and then kept at $-80^{\circ} \mathrm{C}$ until later analysis.

All blood analysis was completed on stored samples, using commercially available assay kits. Serum IL-6 values were determined using ELISA technique (Invitrogen, Camirillo, CA, USA). The intra-assay coefficient of variation (CV) for IL-6 was $7.4 \%$; with an interassay $\mathrm{CV}$ of $9.9 \%$. Invitrogen reports a sensitivity of $<0.09 \mathrm{pg} / \mathrm{mL}$. Tumor necrosis factor a (TNFa) values were also measured using an ELISA technique (Thermo Scientific, Rockford, IL, USA).

The sensitivity of the TNF- $\alpha$ assay is $<1 \mathrm{pg} / \mathrm{mL}$. The intra-assay CV for TNF- $\alpha$ was $4.1 \%$; with an interassay $\mathrm{CV}$ of $11.2 \%$.

\section{Statistical Analysis}

Means and $S E M$ were computed for all variables by group (NH, NL, OH, and OL). To determine if differences existed between the groups $2 \times 2$ analysis of variance (ANOVA) was conducted separately for IL- 6 and TNF- $\alpha$, with $\mathrm{pVO}_{2}$ max units and obesity categories as the main effects. When a significant interaction effect was in ANOVA $(p<.05)$, a Tukey post hoc test was applied to determine which groups were different. To further explore any 
interrelationships, Spearman correlations controlling for differences in body fat were performed between TNF-a, IL-6, and the two metrics of fitness $\left(\mathrm{VO}_{2} \mathrm{FFM}\right.$ and $\left.\mathrm{VO}_{2} \mathrm{~kg}\right)$. Spearman correlations were used because of the polarity of data produced by the group selection; thus the data were not normally distributed. The alpha level was set at $p<.05$. All statistical analysis was computed using SAS version 9.1 (Cary, NC).

\section{Results}

Forty four subjects were initially found to have both high fitness and obesity characteristics. Of the 44 , only 31 had complete data. There were no major $\mathrm{VO}_{2 \max }$ or BMI differences between the $13 \mathrm{OH}$ subjects with incomplete data and the 31 with complete data. After matching each group had 13 females and 18 males and groups did not differ by age $(\sim 10.1 \pm$ $0.8 \mathrm{y})$ or Tanner stage $(\sim 2.3 \pm 0.7)$. Complete group characteristics have been previously published (12) and summarized in Table 2.

Results for IL-6 and TNF- $a$ can be found in Figures 1 and 2, respectively. A significant interaction effect was found between the groups for IL-6 $(p<.05)$. The follow-up Tukey determined that IL-6 levels in the OL group were significantly elevated compared with the $\mathrm{OH}$ and $\mathrm{NH}(p<.05)$ groups. In addition, the NL groups IL-6 levels were significantly elevated compared with the NH group $(p<.05)$. No statistically significant interaction effects were noted for TNF- $\mathbf{\alpha}(p=.057)$. However, since there was a trend $(p=.057)$, a Tukey test was completed for exploratory purposes and a trend was found between the OL and $\mathrm{NH}$ groups differences ( $p=.058$; Figure 2).

The Spearman correlations used to further explore relationships between IL- 6 and both units of $\mathrm{pVO}_{2}$ max were significant and similar: $\mathrm{VO}_{2} \mathrm{FFM}=-0.356 \& \mathrm{VO}_{2} \mathrm{~kg}=-0.361(p=.0001$ for each). No significant relationships were found between either fitness metric or TNF-a: $\mathrm{VO}_{2} \mathrm{FFM}=-0.138(p=.126) \& \mathrm{VO}_{2} \mathrm{~kg}=-0.145(p=.109)$.

\section{Discussion}

This study compared markers of inflammation between normal weight youth of high or low aerobic fitness to obese youth of high or low fitness. The findings show for the first time that higher levels of $\mathrm{VO}_{2 \max }$ are associated with lower levels of IL-6, independent of obesity. Concomitantly, TNF-a did not significantly differ between the groups; however, a trend toward lower values in the NH compared with the OL group $(p=.057)$ was observed and the Spearman correlations were in the right direction (inverse association with $\mathrm{VO}_{2 \max }$ ), suggesting a potential relationship between fitness and obesity on the one hand and TNF- $a$ on the other.

The relationship between obesity (BMI or skinfolds) and inflammation has been well established $(7,13,23)$; however, the contribution of $\mathrm{VO}_{2 \max }$ on the obesity related inflammation is unclear (11). The findings of this investigation suggest IL-6 is more related to $\mathrm{VO}_{2 \max }$ than fatness, whereas the results of Halle et al. (11) suggest that TNF-a is more related to fatness than $\mathrm{VO}_{2 \max }$. One possible explanation for the discrepancy could be the polarized $\mathrm{pVO}_{2}$ max criteria and $\mathrm{BMI} \%$ used for group determination. Halle et al. (11) split their subjects into two groups with normal weight being defined as a BMI $<22.5 \mathrm{~kg} / \mathrm{m}^{2}$ and obesity defined as BMI $>22.5 \mathrm{~kg} / \mathrm{m}^{2}$. Based on the age and sex of the Halle subjects, the BMI percentile for inclusion in their obese group would have been between the 76th and 95th percentile; thus some subjects in their "obese" group were not obese based on the CDC definition of obesity. Including nonobese subjects in an "obese" group is confounding because alterations to resting hormonal levels that influence inflammation occur around 30\% body fat (5) or the 85th BMI percentile (6). Further, Halle et al. (11) defined high-fit 
adolescents as having a maximal MET capacity $\geq 5$ METs and low-fit adolescents have a maximal MET capacity < 5 METs. Possessing a maximal MET capacity of even 6 has been considered very low-fit (16). When estimating our data, low-fit subjects had an average maximal MET capacity of 8.5 in the normal weight and 6.5 for the obese weight groups. Therefore, it is likely that some of subjects in the Halle study considered "high-fit" were not actually high-fit. Subject inclusion criteria used by Halle et al. could have led to some spurious findings which likely do not exist in the current study due to the novel $\mathrm{VO}_{2 \max }$ and BMI percentile criteria used for group determination.

In the present investigation IL-6 was elevated in the NL group, but not in the $\mathrm{OH}$ group, which further suggests that elevated $\mathrm{VO}_{2 \max }$ can result in lower IL-6 levels, independent of obesity. This could be related to the fact that IL- 6 has both pro and anti-inflammatory characteristics. During exercise muscle has been found to be a major producer of IL-6, possibly to reduce inflammation or maintain blood glucose levels (9). Therefore, our conclusion that IL-6 levels are more associated with fitness than fatness would seem appropriate.

In the present investigation, the trend for higher TNF- $\alpha$ levels in the NH compared with the OL group ( $p=.057$ ) may help explain some of the elevation in IL-6, since TNF- $\alpha$ is known to stimulate IL-6 through autocrine/paracrine mechanisms $(8,20,22)$. However, our finding that TNF- $\alpha$ was not significantly elevated, despite increased IL-6 is supported by the findings of Russell et al. (20). Russell et al. (20) found TNF- $\alpha$ receptors to be elevated in obese adolescent girls, which would allow TNF- $\boldsymbol{\alpha}$ to bind to its receptor more easily and have a greater effect (such as IL-6 stimulation) without a need for increased circulating TNF- $\alpha$ concentration. Furthermore, TNF- $\alpha$ has been shown to act via autocrine/paracrine mechanisms and increased TNF-a receptors, specifically TNF receptor 2 (1) which would help promote the increase in IL-6 with only slightly higher levels of TNF-a in the OL group. However, difference in TNF- $\alpha$ of approximately $0.5 \mathrm{pg} / \mathrm{mL}$ may not be physiologically significant, but the potential increase in TNF- $\alpha$ receptors found in many tissues including adipose tissue (15), may be what permitted the increased IL-6 levels in the present investigation. Without the measurement of TNF- $\alpha$ receptor levels this explanation is only speculation.

Predicted $\mathrm{VO}_{2 \max }$ and body fat percentage were estimated which is a limitation of the present investigation. Estimations were used because data collection occurred in schools with issues of 1) limited space for metabolic equipment and 2) transportation of the necessary metabolic equipment. However, our method for predicting $\mathrm{VO}_{2 \max }$ was strong with a correlation of 0.80 with measured $\mathrm{VO}_{2 \max }$ and a standard error of $4 \mathrm{~mL} / \mathrm{kg} / \mathrm{min}$ (17). In addition using the polarized groups should have eliminated some of the ambiguity between groups. Skinfolds were measured in triplicate by trained staff using NHANES procedures (18). The staff were trained by the same individual (RGM) and met strict certification and quality control criteria. Thus, we do not feel these limitations affect our findings. Finally, FFM is not a direct measure of muscle mass. Using FFM theoretically eliminates fat mass and focuses more on metabolically active tissue which may better reflect the capacity of the muscle although our results at present do not suggest using $\mathrm{VO}_{2} \mathrm{FFM}$ versus $\mathrm{VO}_{2} \mathrm{~kg}$ matters.

The present study found that a higher $\mathrm{VO}_{2 \max }$, expressed in either units of FFM or total body mass, was associated with a lower level of IL-6. In addition, there was a trend for TNF- $\alpha$ to be inversely related to both obesity and $\mathrm{VO}_{2 \max }$ (expressed in either units (FFM or $\mathrm{mL} / \mathrm{kg} / \mathrm{min}$ ). Based on these results, the association between $\mathrm{VO}_{2 \max }$ and IL-6 appears independent of fatness; thus, perhaps IL-6 in youth is derived mainly from muscle tissue. The trends in TNF- $\alpha$ may be a function of age or early puberty, perhaps the subjects were 
too young to develop an adult proinflammatory profile. Future investigations should examine the source of IL-6 in a longitudinal study of children, including the period in development when adolescents begin to demonstrate adult-like inflammatory profiles, and the degree to which obesity and fitness influence autocrine/paracine action of TNF- $\alpha$ and TNF- $\alpha$ receptors to determine whether these are influencing IL-6. Our findings also suggest that when studying the relationship between inflammation and $\mathrm{VO}_{2 \max }$ either unit of expression ( $\mathrm{mL} / \mathrm{kg} / \mathrm{min}$ or $\mathrm{mL} / \mathrm{kg}_{\mathrm{FFM}} / \mathrm{min}$ ) may be appropriate. However, this may be an artifact of the polar nature of our groups. Future studies including subjects considered overweight should be done to investigate this relationship further.

\section{Acknowledgments}

Partially funded by NIH NINR01837.

\section{References}

1. Bazzoni F, Beutler B. The tumor necrosis factor ligand and receptor families. N. Engl. J. Med. 1996; 334:1717-1725. PubMed doi:10.1056/NEJM199606273342607. [PubMed: 8637518]

2. Beavers KM, Brinkley TE, Nicklas BJ. Effect of exercise training on chronic inflammation. Clin. Chim. Acta. 2010; 411(11-12):785-793. PubMed doi:10.1016/j.cca.2010.02.069. [PubMed: 20188719]

3. Caballero AE. Endothelial dysfunction in obesity and insulin resistance: a road to diabetes and heart disease. Obes. Res. 2003; 11(11):1278-1289. PubMed doi:10.1038/oby.2003.174. [PubMed: 14627747]

4. Centers for Disease Control and Prevention [Internet]. USA: [cited $2011 \mathrm{Feb} 14]$. Available from http://www.cdc.gov/nchs/about/major/nhanes/growthcharts/charts.html

5. Considine RV, Sinha MK, Heiman ML, Kriauciunas A, Stephens TW, Nyce MR, et al. Serum immunoreactive-leptin concentrations in normal-weight and obese humans. N. Engl. J. Med. 1996; 334:292-295. PubMed doi:10.1056/NEJM199602013340503. [PubMed: 8532024]

6. Dedoussis GVZ, Kapiri A, Samara A, et al. Expression of inflammatory molecules and associations with BMI in children. Eur. J. Clin. Invest. 2010; 40(5):388-392. PubMed doi:10.1111/j. 1365-2362.2010.02277.x. [PubMed: 20345379]

7. Eder K, Baffy N, Falus A. The major inflammatory mediator interleukin-6 and obesity. Inflamm. Res. 2009; 58:727-736. PubMed doi:10.1007/s00011-009-0060-4. [PubMed: 19543691]

8. Eliakim A, Scheett TP, Newcomb R, Mohan S, Cooper DM. Fitness, training, and the growth hormone ${ }^{\circledR}$ insulin-like growth factor I axis in prepubertal girls. J. Clin. Endocrinol. Metab. 2001; 86(6):2797-2802. PubMed doi:10.1210/jc.86.6.2797. [PubMed: 11397890]

9. Fasshauer M, Klein J, Lossner U, Paschke R. Interleukin (IL)-6 mRNA expression is stimulated by insulin, isoproterenol, tumour necrosis factor alpha, growth hormone, and IL-6 in 3T3-L1 adipocytes. Horm. Metab. Res. 2003; 35(3):147-152. PubMed doi:10.1055/s-2003-39075. [PubMed: 12734774]

10. Febbraio MA, Pedersen BK. Muscle-derived interleukin-6: mechanisms for activation and possible biological roles. FASEB J. 2002; 16(11):1335-1347. PubMed doi:10.1096/fj.01-0876rev. [PubMed: 12205025]

11. Van Gaal LF, Mertens IL, De Block CE. Mechanisms linking obesity with cardiovascular disease. Nature. 2006; 444(7121):875-880. PubMed doi:10.1038/nature05487. [PubMed: 17167476]

12. Halle M, Korsten-Reck U, Wolfarth B, Berg A. Low-grade systemic inflammation in overweight children: impact of physical fitness. Exerc. Immunol. Rev. 2004; 10:66-74. PubMed. [PubMed: 15633587]

13. Hosick PA, McMurray RG, Hackney AC, Battaglini CL, Combs TP, Harrell JS. Differences in the GH-IGF-I axis in children of different weight and fitness status. Growth Horm. IGF Res. 2012; 22(2):87-91. PubMed doi:10.1016/j.ghir.2012.02.007. [PubMed: 22436514] 
14. Hotamisligil G, Shargill N, Spiegelman BM. Adipose expression of tumor necrosis factor-alpha: direct role in obesity-linked insulin resistance. Science. 1993; 259:87-91. PubMed doi:10.1126/ science.7678183. [PubMed: 7678183]

15. Maachi M, Piéroni L, Bruckert E, Jardel C, Fellahi S, Hainque B, et al. Systemic low-grade inflammation is related to both circulating and adipose tissue TNFalpha, leptin and IL-6 levels in obese women. Int J Obes Relat Metab Disord. 2004; 28(8):993-7. [PubMed: 15211360]

16. Martin LJ, Woo JG, Daniels SR, Goodman E, Dolan LM. The relationships of adiponectin with insulin and lipids are strengthened with increasing adiposity. J. Clin. Endocrinol. Metab. 2005; 90(7):4255-4259. PubMed doi:10.1210/jc.2005-0019. [PubMed: 15870125]

17. McMurray RG, Andersen LB. The infl uence of exercise on the metabolic syndrome in youth: a review. Am J Lifestyle Med. 2010; 4:176-186. doi:10.1177/1559827609351234.

18. McMurray RG, Guion WK, Ainsworth BE, Harrell JS. Predicting aerobic power in children. A comparison of two methods. J Sports Med Phys Fitness. 1998; 38(3):227-233. PubMed. [PubMed: 9830830]

19. McMurray RG, Hosick PA, Cooper DM. The relationships between leptin and measures of fitness and fatness are dependent upon obesity status in youth. Pediatr. Exerc. Sci. 2010; 22(2):195-204. PubMed. [PubMed: 20567041]

20. National Health Examination Survey. Vital and Health Statistics. Department of Health, Education, and Welfare (DHEW); 1974. Series 11Publication \#74-1614:2-3

21. Petersen AC, Crockett L, Richards M, Boxer A. A self-report measure of pubertal status: reliability, validity and initial norms. J. Youth Adolesc. 1988; 17(2):117-133. doi:10.1007/ BF01537962.

22. Russell M, Bredella M, Tsai P, et al. Relative growth hormone deficiency and cortisol excess are associated with increased cardiovascular risk markers in obese adolescent girls. J. Clin. Endocrinol. Metab. 2009; 94:2864-2871. PubMed doi:10.1210/jc.2009-0380. [PubMed: 19435823]

23. Slaughter MH, Lohman TG, Boileau RA, et al. Skinfold equations for estimation of body fatness in children and youth. Hum. Biol. 1988; 60(5):709-723. PubMed. [PubMed: 3224965]

24. Weisberg SP, McCann D, Desai M, Rosenbaum M, Leibel RL, Ferrante AW Jr. Obesity is associated with macrophage accumulation in adipose tissue. J. Clin. Invest. 2003; 112:1796-1808. PubMed. [PubMed: 14679176]

25. Willerson JT, Ridker PM. Inflammation as a cardiovascular risk factor. Circulation. 2004; 109:II2II10. PubMed. [PubMed: 15173056] 


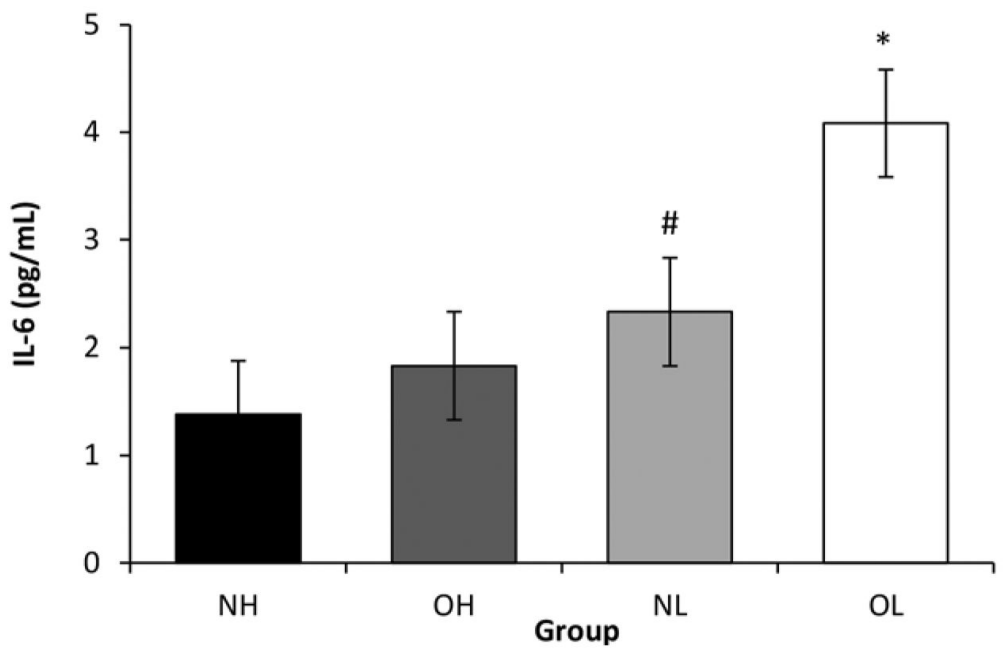

Figure 1.

Mean ( $\pm S E M$ ) resting IL-6 level of the normal weight high-fit (NH), normal weight low-fit $(\mathrm{NL})$, obese high-fit $(\mathrm{OH})$, and obese low-fit (OL) groups. ${ }^{*} p<.05$ from $\mathrm{NH}$ and $\mathrm{OH} \# p<$. 05 from $\mathrm{NH}$ only 


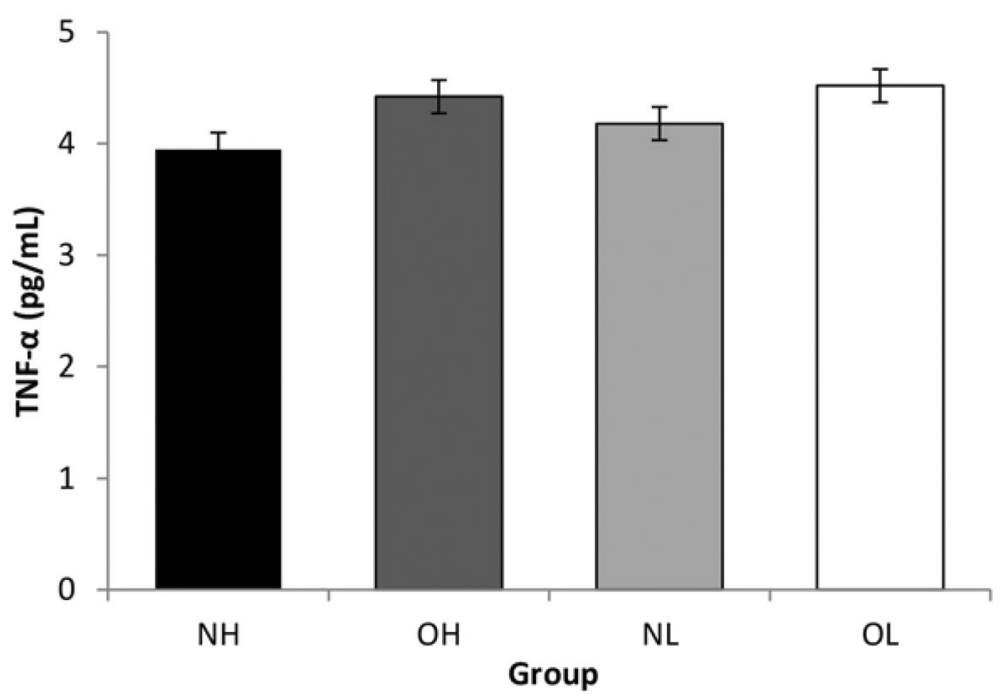

Figure 2.

Mean $( \pm S E M)$ resting TNF- a level of the normal weight high-fit $(\mathrm{NH})$, normal weight lowfit (NL), obese high-fit $(\mathrm{OH})$, and obese low-fit (OL) groups. 


\section{Table 1}

The 33rd\% (low-fit) and 66th\% (high-fit) cut-points of the presented by gender and age

\begin{tabular}{lccc}
\hline Gender & Age & Fitness 33rd\% $\left(\mathbf{m L} / \mathbf{k g}_{\mathbf{F F M}} / \mathbf{m i n}\right)$ & Fitness $66 \mathbf{6 h} \%\left(\mathbf{m L} / \mathbf{k g}_{\mathbf{F F M}} / \mathbf{m i n}\right)$ \\
\hline Male & 8 & 51.8 & 59.3 \\
Female & 8 & 49.9 & 58.7 \\
Male & 9 & 52.4 & 59.8 \\
Female & 9 & 49.8 & 57.1 \\
Male & 10 & 49.2 & 57.8 \\
Female & 10 & 46.0 & 53.8 \\
Male & 11 & 47.8 & 55.7 \\
Female & 11 & 43.4 & 50.4 \\
Male & 12 & 47.1 & 53.2 \\
Female & 12 & 45.5 & 52.0 \\
\hline
\end{tabular}


Table 2

Mean $\pm S D$ of anthropometric and fitness variables presented by group

\begin{tabular}{|c|c|c|c|c|}
\hline & Normal High Fitness & Normal Low Fitness & Obese High Fitness & Obese Low Fitness \\
\hline BMI $\left(\mathrm{kg} / \mathrm{m}^{2}\right)$ & $17.4 \pm 5.7^{\dagger t}$ & $17.6 \pm 1.7 \%$ & $27.7 \pm 4.9^{* \#}$ & $27.7 \pm 3.4^{* \#}$ \\
\hline BMI percentile & $53.2 \pm 20.8^{\dagger t}$ & $56.8 \pm 24.0^{\dagger \neq t}$ & $97.8 \pm 1.5^{* \#}$ & $98.1 \pm 1.2^{* \#}$ \\
\hline Fat percentage & $17.4 \pm 5.7 \dagger t$ & $16.0 \pm 6.6 \%$ & $36.7 \pm 11.0 * \#$ & $32.2 \pm 7.3^{* \#}$ \\
\hline Fat Free Mass (kg) & $27.9 \pm 4.1^{\dagger t}$ & $30.8 \pm 5.4 \%$ & $37.1 \pm 7.4^{* \#}$ & $40.9 \pm 6.0^{* \#}$ \\
\hline $\mathrm{VO}_{2} \mathrm{FFM}$ & $62.1 \pm 8.1 \%$ & $35.4 \pm 6.6^{\dagger^{*}}$ & $64.8 \pm 10.3$ & $35.1 \pm 6.6^{t^{*}}$ \\
\hline $\mathrm{VO}_{2} \mathrm{~kg}$ & $51.3 \pm 7.5^{\#+t . t}$ & $29.8 \pm 6.4^{*}+*$ & $40.8 \pm 9.0^{* \# ; t}$ & $23.9 \pm 5.6^{* \# \dagger}$ \\
\hline \multicolumn{5}{|l|}{ p $<0.05$ from $\mathrm{NH}}$, \\
\hline \multicolumn{5}{|l|}{${ }_{\mathrm{p}}^{\#}<0.05$ from $\mathrm{NL}$} \\
\hline \multicolumn{5}{|l|}{$t_{\mathrm{p}}<0.05$ from $\mathrm{OH}$} \\
\hline$F_{p}<0.05$ from $\mathrm{O}$ & & & & \\
\hline
\end{tabular}

